\title{
Evaluating Extreme Rainfall Changes over Taiwan Using a Standardized Index
}

\author{
Yu-Shiang Tung ${ }^{1, *}$, Cheng-Ta Chen ${ }^{2}$, Seung-Ki Min ${ }^{3}$, and Lee-Yaw Lin ${ }^{1}$ \\ ${ }^{1}$ National Science and Technology Center for Disaster Reduction, Taipei City, Taiwan, R.O.C. \\ ${ }^{2}$ Department of Earth Sciences, National Taiwan Normal University, Taipei City, Taiwan, R.O.C. \\ ${ }^{3}$ Division of Environmental Science and Engineering, Pohang University of Science and Technology (POSTECH), Pohang, \\ Gyeongbuk, Korea
}

Received 20 July 2015, revised 18 February 2016, accepted 13 June 2016

\begin{abstract}
The annual daily maximum precipitation (rx1day) is widely used to represent extreme events and is an important parameter in climate change studies. However, the climate variability in rxlday is sensitive to outliers and has difficulty representing the characteristics of large areas. We propose to use the probability index (PI), based on the cumulative density function (CDF) of a generalized extreme value (GEV) distribution to fit and standardize the rx1day to represent extreme event records in this study. A good correlation between the area-averaged PIs of the observed stations and those of the gridded dataset can be found over Taiwan. From the past PI records, there is no distinct trend in western Taiwan before the end of the $20^{\text {th }}$ century, but a climate regime change happened during 2002 - 2003. The dual change effects from both the variance and linear trend of extreme events are identified over the northeastern and southern parts of Taiwan, along with the island's central and southern regions, showing different abrupt changing trends and intensity. The PI can also be calculated using climate projection data to represent the characteristics of future extreme changes. The climate variability of PIs on the present (ALL) and future (RCP4.5 and RCP8.5) scenarios were evaluated using the 16 Couple Model Intercomparison Projects Phase-5 models (CMIP5). The simulated present fluctuations in PIs are smaller than those of actual observations. In the $21^{\text {st }}$ century, the RCP8.5 scenario shows that the PI significantly increases by $10 \%$ during the first half of the century, and $14 \%$ by the end of the century.
\end{abstract}

Key words: Extreme rainfall, Climate change, GEV

Citation: Tung, Y. S., C. T. Chen, S. K. Min, and L. Y. Lin, 2016: Evaluating extreme rainfall changes over Taiwan using a standardized index. Terr. Atmos. Ocean. Sci., 27, 705-715, doi: 10.3319/TAO 2016.06.13.03

\section{INTRODUCTION}

Taiwan features a complex topography characterized by mountainous regions and rugged terrain, where rivers are short, valleys are narrow and geological features are fragile. Taiwan is also frequently attacked by North-West Pacific (NWP) typhoons. Thus, the ability to accurately assess extreme rainfall variations is important to better mitigate typhoon damage (ex: Typhoon Morakot in 2008) and manage water resources. Previous studies have verified that the annual maximum precipitation is highly related to the contribution from typhoon rainfall (Chen and $\mathrm{Lu}$ 2007; $\mathrm{Lu}$ et al. 2007). The annual extreme rainfall events recorded by observation stations are often viewed as independent cases

\footnotetext{
* Corresponding author

E-mail:ystung@ncdr.nat.gov.tw
}

(Chen and Lu 2007; Lu et al. 2007; Su et al. 2012) when calculating the return values and periods during flood management analysis and modelling (Chu et al. 2013). Despite the increase in available satellite and radar data, the lack of high spatial density in long-term observed records makes it difficult to validate the variation in extreme events over Taiwan ( $\mathrm{Lu}$ et al. 2007). Consequently, it is necessary to use a parameter that is able to represent a complete dataset regarding the long-term changes in the frequency and intensity of unexpected extreme rainfall events (Meehl et al. 2000; Kharin et al. 2013).

Extreme rainfall changes in Asia have been a key research topic in many studies. Many researches on heavy rainfall variance are based on observed station records dating from the 1950s to the 2000s. In global warming experiments, Freychet et al. (2015) stated that the heavy rainfall 
induced by the summer monsoon in East Asia exhibited more frequently extreme precipitation due to the moisture flux change. Significant positive trends in precipitation extreme events have been observed over the Yangtze River basin and northwestern China (Endo et al. 2005; Zhai et al. 2005). Endo et al. (2009) showed that there was an increasing trend in the extreme precipitation indices of stations located in south Asia (southern Vietnam, north Myanmar, and northern islands in the Philippines). The observation data used in these researches employs reanalysis, satellite or low density stations datasets. Unfortunately, up until now, there has been only a few studies (Lu et al. 2007; Shiu et al. 2009; Su et al. 2012) regarding the extreme rainfall change using observation stations over Taiwan. In order to validate the extreme rainfall variance over complicated Taiwan terrain in a time scale of more than 10 years, high density (or grid) and long records of observation are necessary.

The current general consensus regarding climate change is that as the temperature continues to rise, vapor will also increase in proportion (Liu et al. 2009). To analyse the probability of increases in extreme events, such as floods or droughts, a viable approach is to study the changes in the mean precipitation state and variance (Meehl et al. 2000; Kharin et al. 2013; Fischer and Knutti 2015). However, it should be noted that the extreme rainfall events simulated by models are influenced by many local complex factors (ex: deep convection schemes, heat contract, large-scale circulation, etc.). The annual maximum daily precipitation index (rx 1day) is frequently used to measure extreme rainfall events year by year. The global rx1day of land-based observation stations have validated a $7.2 \% \mathrm{~K}^{-1}$ increase in the period 1960 - 2009 (Westra et al. 2013), as well as a $6 \% \mathrm{~K}^{-1}$ in the late $20^{\text {th }}$ century from $1986-2005$ in Couple Model Intercomparison Projects Phase 5 (CMIP5) multimodel experiments (Kharin et al. 2013). These studies represent global-scale information, but the data are considered too rough for downstream applications in Taiwan.

The precipitation criterion definition for extreme rainfall (ex: the $95^{\text {th }}, 99^{\text {th }}$ percentile or $200 \mathrm{~mm}^{\text {day }}{ }^{-1}$ etc.) is often used to measure the intensity and frequency of extreme events. Shiu et al. (2009) analysed the observed station measurement dataset in Taiwan, revealing that relatively wet and dry regions were becoming wetter and drier respectively in the recent decade. Chen and $\mathrm{Lu}$ (2007) used the fixed-percentile method to estimate the extreme rainfall frequency in Eastern Taiwan, but this method is sensitive to the climatology record length and whether the observation stations are located on the windward side or not. Many difficulties need to be overcome in validating both the spatial and temporal extreme rainfall variance over Taiwan. When studying the changes in extreme rainfall and properly estimating the area-mean to represent regional characteristics, a unified index that is not sensitive to topography is preferred. Furthermore, this unified index can be used to show the climate variability and regime-change from the annual fluctuation in extreme events in space-time.

This study also used projections of the state-of-theart CMIP5 models to evaluate future changes in extreme rainfall in Taiwan. The best assessment for explaining the uncertainty and confidence in multi-models comes from methods that collect the best-models or calculate unequalweighting multi-models to ensemble the mean (MME) to assess the present climate phenomena (Kitoh and Uchiyama 2006; Miao et al. 2014), and also the future climate projections (Jiang and Tian 2013; Lee and Wang 2014). Knutti et al. (2010) presented that those methods that performed well for present-day climate projecting may not be good for future climate projections, due to the indefinite contributions of individual imperfect models. The uncertainty stems from the limited theoretical understanding (aerosols affect cloud formation), parameterizations (many small-scale processes integrated in a model could affect large-scale results), and model structural problems. These unknown factors and the systematic biases of models are still not well understood. Nevertheless, the results show that using equal-weighting MME is considered better than using projections from individual models. The assessment from multiple models generates a realizable range of spread, which results in many different types of future climate projections.

We propose a method that can effectively validate the extreme rainfall variance and trend over Taiwan, and reduce the impact of outliers associated with complicated topography. These methodologies, the high-resolution observation data, and the multi-model projection datasets, are described in section 2 . The climate variability of the observation validation is shown in section $3.1-3.2$. The simulation pathways from the present climate to future projections are discussed in section 3.3.

\section{DATA AND METHOD}

\subsection{Observation and Models}

The annual maximum daily precipitation (rx1day, referred to as the extreme precipitation index hereafter) of Taiwan is highly related to orographic precipitation, typhoons and mesoscale convective systems (MCS). A high spatial-temporal resolution dataset, the TCCIP-I (National Science and Technology Center for Disaster Reduction / Taiwan Climate Change Production and Information Platform phase I) gridded $5 \mathrm{~km} \times 5 \mathrm{~km}$ and daily spatialtemporal resolution data (TCCIP_5km) from 1960 - 2009 (Weng and Yang 2012), is used as the observation dataset to calculate the rx1day for Taiwan. This dataset collected precipitation data records from the Central Weather Bureau (CWB), Water Resource Agency, the Irrigation Association and Taiwan Power Company (TPC). In addition to the gridded TCCIP_5km data, daily measurement of 23 stations (TW_STN) operated by the CWB covering the same period 
is also analysed for comparison.

Considering the data availability, projections of 16 models in CMIP5 were selected (Table 1). When presentday (1960 - 2009) climate is considered, projections of all 16 models (ALL) were used, and shown good consistence with observations. For future climate projections, the data of weaker warming scenario RCP4.5 (indicated as RCP45) and the stronger warming scenario RCP8.5 (indicated as RCP85) were employed for comparison. The rx1day data is available from the dataset for Climate Extreme Indices (CLIMDEX) (Sillmann et al.2013a, b), of the model outputs of the Canadian Centre for Climate Modeling and Analysis (CCCMA) archive.

\subsection{Probability Index and Data Processing}

The outlier extreme rainfall recorded by observation stations or grids at the windward side, as well as models with different horizontal resolutions (see below section 3) can cause large errors in estimating changing extreme precipitation index trends. Moreover, it may not be a proper parameter to represent the changing characteristics of extreme events. Min et al. $(2011,2013)$ rendered the annual extreme indices by fitting its cumulative distribution function (CDF) with the generalized extreme value (GEV) distribution [Eq. (1)], which is a function of three parameters, the shapes $(\xi)$, the skewness $(\sigma)$, and the location $(\mu)$. Following the $\mathrm{CDF}$ curve, these three parameters converted the annual ex- treme indices (rx1day) into a probability index (PI) as seen in Fig. 1.

$F(x ; \mu, \sigma, \xi)=\left\{\begin{array}{cr}e^{-e^{-\frac{x-\mu}{\sigma}},}, \quad \xi=0 \\ e^{-\left(1+\xi \frac{x-\mu}{\sigma}\right)^{-\xi^{-1}}}, & 1+\xi \frac{x-\mu}{\sigma}>0\end{array}\right.$

Take in Fig. 1, the rx1days of $120\left(\mathrm{~mm} \mathrm{day}^{-1}\right)$ is converted to a PI of 0.74 . This method transfers rx1day to PI using the CDF of GEV distributions to standardize the data. The benefits of using PI instead of rx1day include: the influence of outliers is minimized, the area-mean of PI will not be dominated by the local maximums, and data from different sources (station observation, satellite retrieval, model projection of different resolutions) can be compared together.

To compare projection data with gridded observation data, the rx1day on original grid points of 16 Couple General Circulation Model (CGCM) were transferred to PIs first. Because PI is a standardized index, we can interpolate PI to the same $0.5^{\circ} \times 0.5^{\circ}$ grid-mesh as in TCCIP_5km. Additional details regarding the validation are in section 3.1 .

\subsection{Change-Point Analysis Method}

We are concerned with the abrupt changes in the observation rx1day (and the associated PI) in the mean statement and variance fluctuation. The early Moving T-test method

Table 1. The 16 CMIP5 models list used in this study. The different short name, maintain center/country and resolution are also displayed.

\begin{tabular}{|c|c|c|c|}
\hline No. & Model ID & Modeling Center / Country & Resolution \\
\hline 1 & ACCESS1-0 & $\begin{array}{l}\text { Commonwealth Scientific and Industrial Research Organization and Bureau of Meteorology (CSIRO-BOM), } \\
\text { Australia }\end{array}$ & $192 \times 145$ \\
\hline 2 & bcc-csm1-1 & Beijing Climate Center (BCC), China Meteorological Administration, China & $128 \times 64$ \\
\hline 3 & BNU-ESM & College of Global Change and Earth System Science (GCESS), Beijing Normal University, China & $128 \times 64$ \\
\hline 4 & CanESM2 & Canadian Centre for Climate Modelling and Analysis (CCCMA), Canada & $128 \times 64$ \\
\hline 5 & CCSM4 & National Center for Atmospheric Research (NCAR), USA & $288 \times 192$ \\
\hline 6 & CMCC-CM & Centro Euro-Mediterraneo per I Cambiamenti Climatici (CMCC), Germany & $480 \times 240$ \\
\hline 7 & CNRM-CM5 & $\begin{array}{l}\text { Centre National de Recherches Météorologiques / Centre Européen de Recherche et Formation Avancée en } \\
\text { Calcul Scientifique (CNRM-CERFACS), France }\end{array}$ & $256 \times 128$ \\
\hline 8 & CSIRO-Mk3-6-0 & $\begin{array}{l}\text { Commonwealth Scientific and Industrial Research Organization in collaboration with Queensland Climate } \\
\text { Change Centre of Excellence (CSIRO-QCCCE), Australia }\end{array}$ & $192 \times 96$ \\
\hline 9 & FGOALS-g2 & $\begin{array}{l}\text { LASG, Institute of Atmospheric Physics, Chinese Academy of Sciences and CESS, Tsinghua University } \\
\text { (LASG-CESS), China }\end{array}$ & $128 \times 60$ \\
\hline 10 & GFDL-ESM2M & NOAA Geophysical Fluid Dynamics Laboratory (NOAA GFDL), USA & $144 \times 90$ \\
\hline 11 & HadGEM2-ES & Met Office Hadley Centre (MOHC), UK & $192 \times 145$ \\
\hline 12 & IPSL-CM5A-LR & Institut Pierre-Simon Laplace (IPSL), France & $96 \times 96$ \\
\hline 13 & MIROC-ESM & \multirow{2}{*}{$\begin{array}{l}\text { Japan Agency for Marine-Earth Science and Technology, Atmosphere and Ocean Research Institute (The } \\
\text { University of Tokyo), and National Institute for Environmental Studies (MIROC), Japan }\end{array}$} & $128 \times 64$ \\
\hline 14 & MIROC-ESM-CHEM & & $128 \times 64$ \\
\hline 15 & MRI-CGCM3 & Meteorological Research Institute (MRI), Japan & $320 \times 160$ \\
\hline 16 & NorESM1-M & Norwegian Climate Centre (NCC), Norway & $144 \times 96$ \\
\hline
\end{tabular}




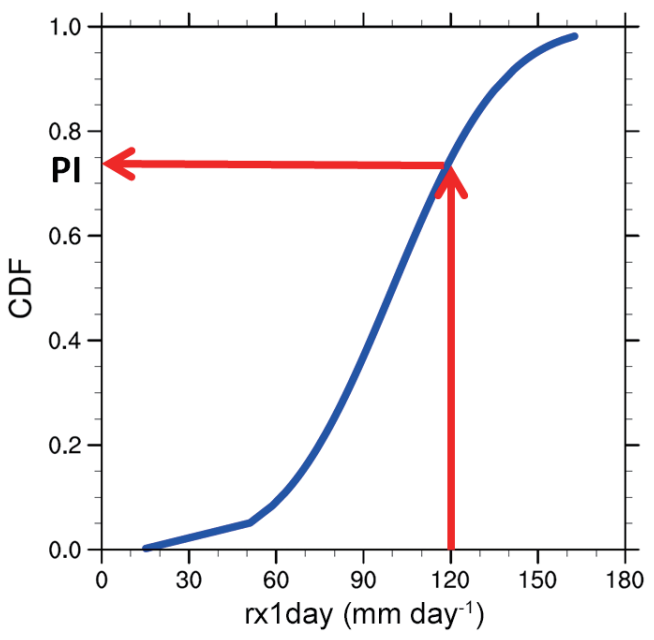

Fig. 1. The rx1day (x-axis) illustration converts into the probability index (PI) (y-axis) from its cumulative distribution function (CDF) curve (blue line). Each $\mathrm{rx} 1$ day $\left(\mathrm{mm} \mathrm{day}^{-1}\right)$ can find the corresponding uniformed PI (follow red arrow lines) which limited 0 to 1 . This curve computed from the 50-year annual indices of each grid follow the generalized extreme value (GEV) distribution.

(Ducré-Robitaille et al. 2003) is sensitive to the sample detection window size, but the change-point analysis method (CPT) is more straightforward and reasonable. The linear CPT (Killick and Eckley 2014) is used to analyse abrupt changes and shift points (time step) in mean and variance in one-dimension signals. While the PIs detect the change point using CPT, the null hypothesis was rejected, and we have $99 \%$ confidence in this result. We define the change point position as the change time step between two climate regimes at the same time.

\section{RESULTS AND DISCUSSION}

\subsection{PI Validation}

Figure 2 shows the rx 1day and the associated PI anomaly curve for Alishan, Kaohsiung, Taipei, and Hualien stations. These stations in four different geographical regions show a large discrepancy in fluctuations and intensities for the rx1day (grey solid lines and refer left y-axis). The TW_STN trends over south-west Taiwan (Figs. 2a, b) are larger than those in the north-east (Figs. 2c, d). For example, the mountainous station, Alishan (Fig. 2a), in Central Taiwan displays a large amplitude, as well as the 50-year linear trend $\left(2.92 \mathrm{~mm}\right.$ day $^{-1}$ year $\left.^{-1}\right)$, compared to the other stations of plains. This phenomenon can be found for other stations located at the prevailing windward side of the mountains in south-western Taiwan. Thus, before conducting climate change assessment, we believe it is necessary to evaluate the area mean trends in both the observational and model data with the uniformed parameter, PI (red dashed lines and refer right $y$-axis in Fig. 2). It can be seen that the fluctuation of rx1day anomaly of Taipei is the smallest among 4 stations, but the PI anomaly fluctuation of Taipei is comparable to others. The largest rx 1day trend happened in Alishan (2.92 $\mathrm{mm} \mathrm{day}^{-1}$ year $\left.^{-1}\right)$, but the largest PI trend happened in Kaohsiung $\left(0.47 \%\right.$ year $\left.^{-1}\right)$ among these four stations. These results distinct a previous study (Lu et al. 2007), and imply a spatial consistency in the variability of rx1day.

The spatial PI trends of station TW_STN and gridded TCCIP_5km datasets shown in Fig. 3 present the local extreme index variances. The trends of southwest Taiwan range from $0.7-0.9 \%$ year $^{-1}$, more significant than those of central and northern (from -0.15 to $0.15 \%$ year $^{-1}$ ) Taiwan (Fig. 3a). We also verified the TW_STN to TCCIP_5km locations where similar trend values imply that these two datasets are coherent. The rx 1day clustered effect by geographic and typhoon attacked tracks but the specific station record analysis individually (Chen and $\mathrm{Lu}$ 2007; $\mathrm{Lu}$ et al. 2007). The gridded TCCIP_5km (Fig. 3b) can show an overall view of climate variability for the whole island, which cannot be displayed using station data TW_STN. More spatial trend distribution details are described in section 3.2.

The PI can be used to represent the annual area-mean climate variability (Min et al. 2011). We demonstrate the consistency between the area-average rx1day and the associated PIs by comparing two observed datasets (TW_STN and TCCIP_5km). The scatter plot in Fig. 4a shows a strong statistical relationship in the annual anomaly from 1960 - 2009 over Taiwan. The straight lines represent the least square regression slope, and the plus sign shows the relationship between rx 1day and PI. The high correlation coefficients of these two specific datasets (TCCIP_5 $\mathrm{km}$ is 0.96 ; TW_STN is 0.94) demonstrate that the PI can represent the rx1day raw performance. The regression slopes show the linear relationships (TCCIP_5 $\mathrm{km}$ is $3.45 \mathrm{~mm} \mathrm{day}^{-1} \%{ }^{-1}$ and TW_STN is $\left.2.96 \mathrm{~mm} \mathrm{day}^{-1} \%{ }^{-1}\right)$, and the regressed standard deviations (TCCIP_5 $\mathrm{km}$ is $0.15 \mathrm{~mm} \mathrm{day}^{-1}$ and TW_STN is $0.16 \mathrm{~mm} \mathrm{day}^{-1}$ ) display the uncertainty range. The high regression slopes imply large variations in rx1day and PIs, as well as the present day trend uncertainty. In contrast, the low regression slopes reveal a strong relationship. Figure $4 \mathrm{~b}$ displays the annual time series PI anomalies on the two observations over Taiwan. The trend is $0.25 \%$ year $^{-1}$ (two datasets are the same). The 5-year means display unclear trends before 2000, which is consistent with the TCCIP_5 $5 \mathrm{~km}$ divided analysis. The inconsistent annual anomaly relationship (correlation coefficient is 0.79 ) is attributed to different periods where the dividing line is 1987 (the correlation coefficient in 1960 - 1987 is $0.48 ; 1988-2010$ is 0.9 ).

Overall, the variances in these two observations are significantly different before 1987 . The lack records inducing the most contribution to rx1day cannot be validated by inference. However, the gridded PI dataset is more reliable in geographic contract than the station records presented in Fig. 5 (refer to Fig. 2). We use TCCIP_5km as the reference observation to compare models in the following assessment. 
We verified the PI performance in extreme rainfall (Fig. 4) and then applied it to the following analysis.

\subsection{Climate Variability}

We divided the geography and county boundary parameters of Taiwan into four regions: north (NOR), center (CEN), south (SOU), and east (EAS) (Fig. 5e) to represent the local climate variability features for the TCCIP_5km dataset. The annual and 5-year area means of PI anomaly are presented in Figs. 5a - c. There is no distinct linear trend for the decadal change in each sub-region before 2000, especially over NOR, CEN, and SOU. Tu et al. (2009) presented the abrupt change in the typhoon count in WNP at 2000, which correlated to the weakening western North Pacific subtropical high (WNPSH). The linear trend over the four regions (the area trends in Fig. 5) demonstrates that the rx1day intensity is related to the location distribution. The gridded data area mean is much better than the station data detection in understanding the extreme rainfall variance over Taiwan.

We tie the PI statistical regressions in 50-year annual
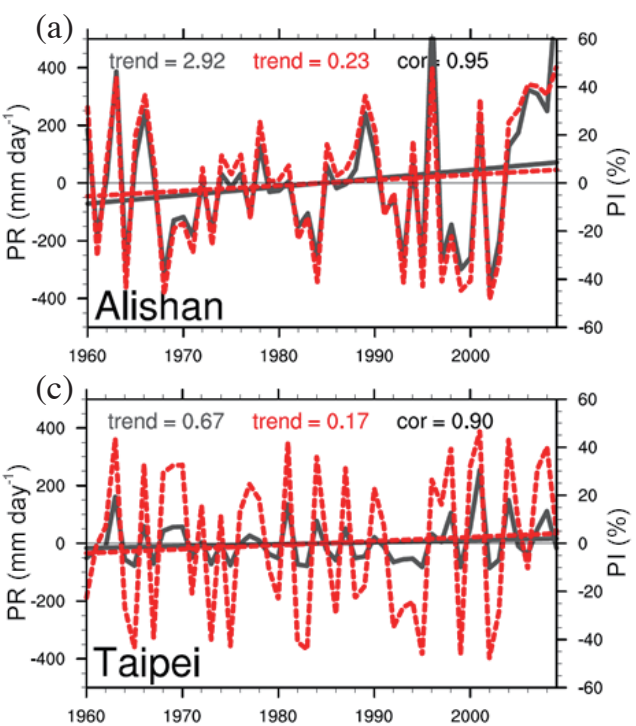

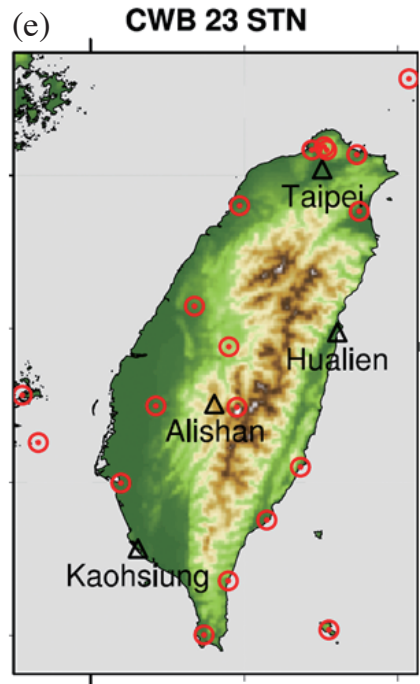

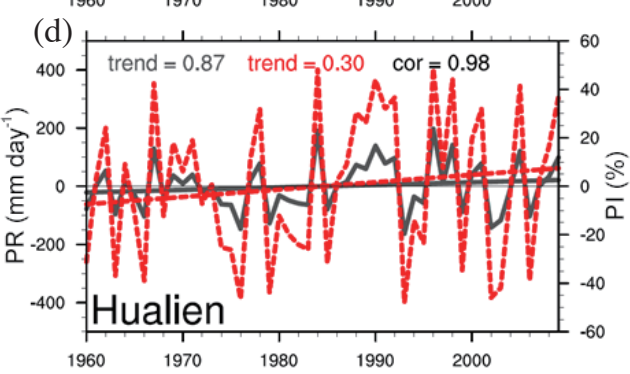

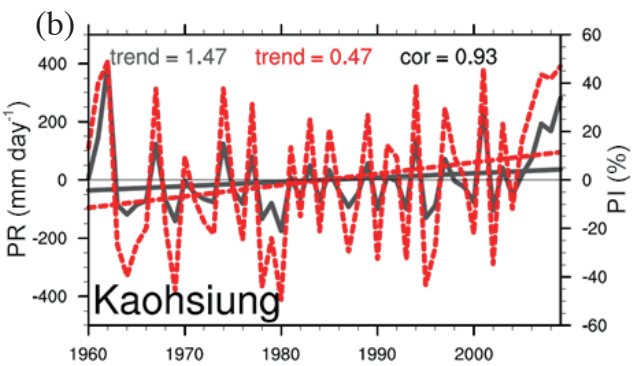

Fig. 2. The 50 years $\left(1960\right.$ - 2009) annual rxlday $\left(\mathrm{mm} \mathrm{day}^{-1}\right)$ (gray solid lines, left y-axis) of CWB historical records and the associated PIs $(\%)$ (read dash line, right y-axis) are displayed. The particular linear trend slopes and correlation coefficient label top of each figure. Each annual curve represents the specific 4 regions of Taiwan, Alishan (a) is Center, Kaohsiung (b) is Southern, Taipei (c) represents Northern and Hualien (d) is Eastern. The topographic locations of 23 station records, which we sampled uniformly, are demonstrated in (e).

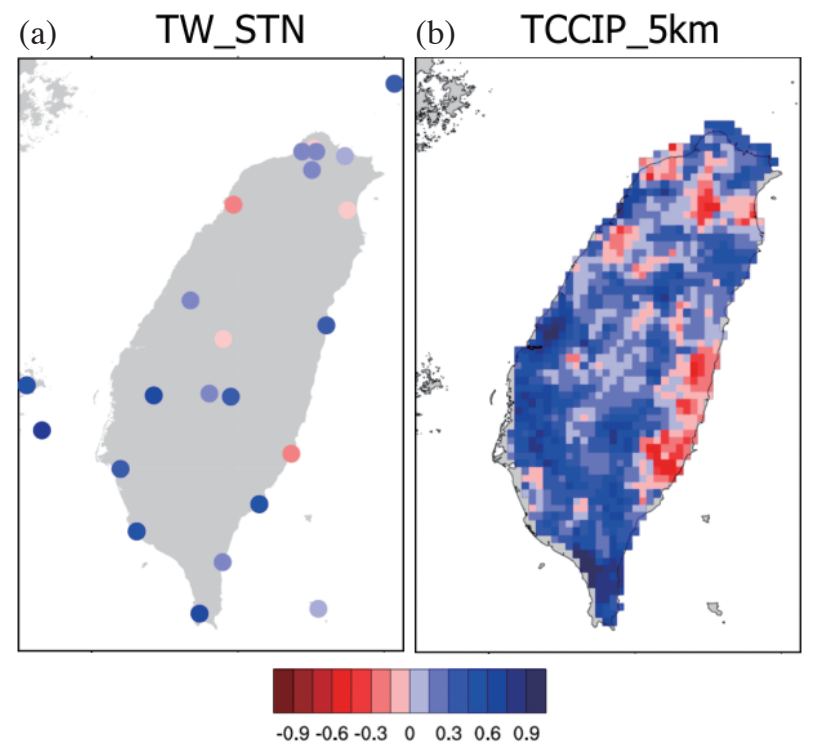

Fig. 3. The linear trends $\left(\%\right.$ year $\left.^{-1}\right)$ spatial distribution of PI compared (a) TW_STN 23 stations and (b) TCCIP_5km. 

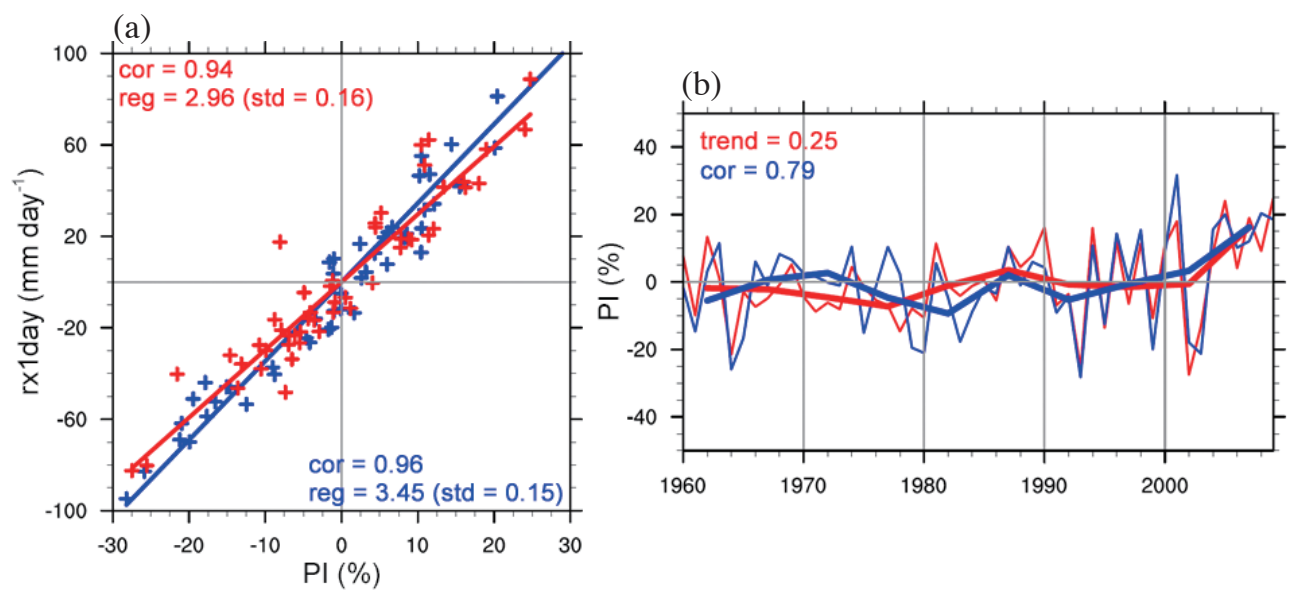

Fig. 4. The statistical relationship between rx 1day and PI of TCCIP_5km and TW_STN over Taiwan. (a) displays the scatterplot of rx 1day anomaly $\left(\mathrm{mm} \mathrm{day}^{-1}\right)$ and corresponding PI (\%) on TCCIP_5 km (blue) and TW_STN (red). The correlation coefficients (cor) and regression slopes [reg $\left(\mathrm{mm}\right.$ day $\left.^{-1} \%^{-1}\right)$ ] on the corners represent the relationship between rx 1day and the associated PI. (b) presents the time series of these two datasets, the thin lines are annual anomaly and the thick are 5-year mean. The correlation coefficient in (b) represents the annual PIs anomaly between these two datasets and the linear trend $\left(\%\right.$ year $\left.{ }^{-1}\right)$ only shows TCCIP_5 $\mathrm{km}$ since the consistency.

(a)
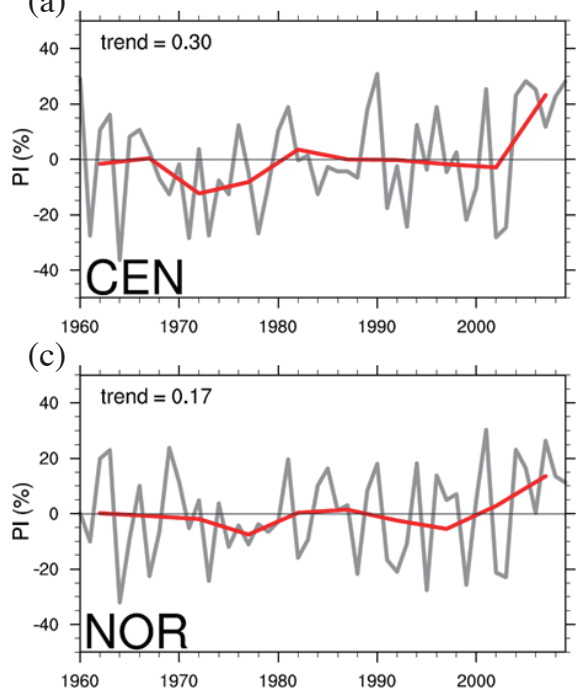

(b)

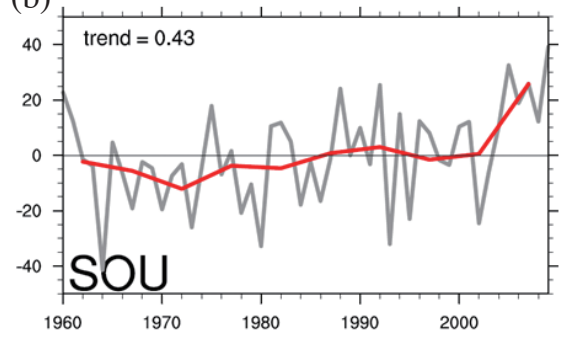

(d)

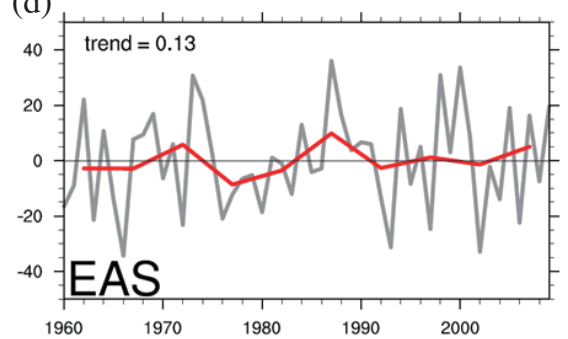

(e)

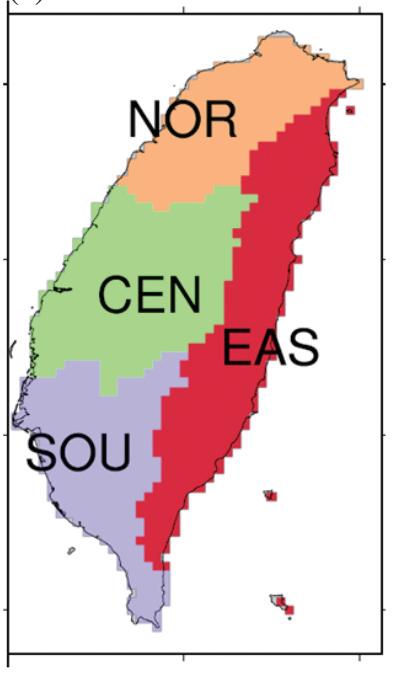

Fig. 5. The TCCIP spatial distribution $5 \mathrm{~km}$ resolution data divided into four regions (e), North (NOR), Center (CEN), South (SOU), and East (EAS). The anomalous PIs (\%) represent the area mean of four regions [(a) - (d)]. The grey lines display annual anomaly and red lines are 5-year mean. The linear trends $\left(\%\right.$ year $\left.{ }^{-1}\right)$ of these four regions also show on the up left side of each figure.

data linear trends over each grid to demonstrate the variability between rx1day and PI (Fig. 4a). Figure 6 represents the spatial distribution trend. The positive trends (cover $82 \%$ land area of Taiwan) appear in southern, western, and east-northern Taiwan, which implies that the probability for extreme rainfall generally increases. These results are consistent with the four region area-mean (refer to Figs. 5a - d). The larger regression slopes discovered over the eastern Taiwan and southwestern mountainous regions reveal that the rx1day of these areas own a large variation in regards to the PI variability in the changing climate (Meehl et al. 2000; Kharin et al. 2013).
Notable signals can be found while looking for the obvious trends combining the low regression slopes areas in Fig. 6. The obvious positive trends (above $0.4 \mathrm{~mm}^{-1 a y^{-1}}$ year $^{-1}$ ) but low regression slopes (below $2 \mathrm{~mm} \mathrm{day}^{-1} \% \mathrm{o}^{-1}$ ) are found in the center-south plain (Changhua, Yunlin, and Tainan) and south coastal regions (Hengchun Peninsula) of Taiwan. The smaller variance of rx1day (low regression slope) along with the positive trends area reveal a significant extreme rainfall increase, which are related to typhoon occurrences (Chen and Lu 2007; Lu et al. 2007) and the associated southwesterly flows. Over northwest Taiwan, the positive trends represent the Taipei basin and the negative trends denote the coastal 


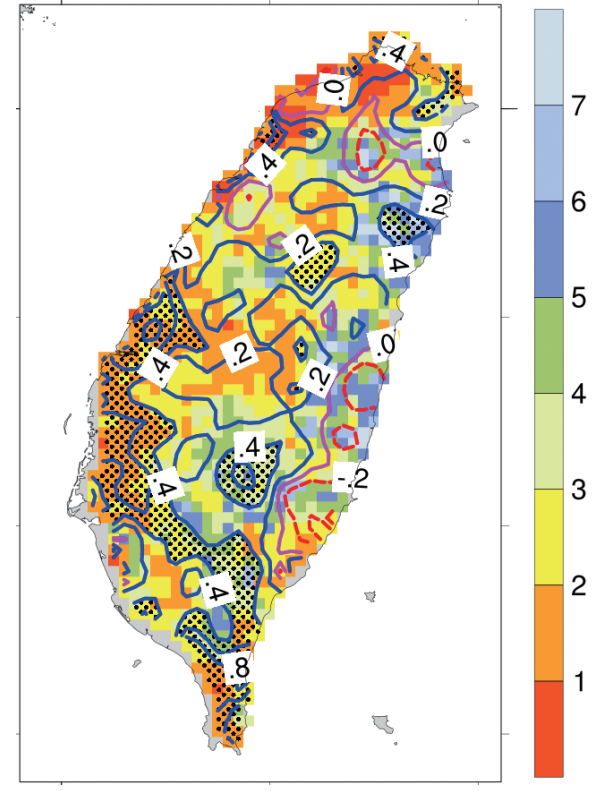

Fig. 6. Spatial distributions of PI trends $\left(\%\right.$ year $\left.^{-1}\right)$ (contours) and the regression slopes $\left(\mathrm{mm} \mathrm{day}^{-1} \%^{-1}\right)$ (shades) between $\mathrm{rx} 1$ day and PI. The lower regression slops represent smaller rx1day variations. Blue contour line reveals positive trend, red display negative trend area, and separated by the magenta line. The dot pattern highlights the trend above $0.4 \mathrm{~mm}_{\text {day }}{ }^{-1}$ year $^{-1}$.

areas. The positive and negative trend pairing over centersouth and north Taiwan imply that the typhoon track moves to the north-westerly vicinity as it passes though. However, as the heavy regression slopes further encompassed east Taiwan, it revealed larger rx 1day variations and lower trends.

Previous studies (Chen and Lu 2007; Su et al. 2012; Chu et al. 2013) analysed the extreme precipitation climate parameters using single station records over Taiwan. The local dataset is so limited that it is difficult to represent the entire island of Taiwan for the climate change assessment. We evaluated climate regime variability using the mean state (CPT_Mean) and variance (CPT_Var) reasonably for the uniformed rx1day from each grid. The change position (year) is validated for the whole 50-year period and divided into distinct periods using CPT. The CPT_Mean intensity is the different climatology of two periods separated by change point, and CPT_Var is the variance. The CPT_Mean separates at 2003 - 2004 implying the climatology state jumps from the first (1960 - 2003) into the second phase (2004 2009) (Fig. 7a), and the intensity is $17.02 \mathrm{~mm} \mathrm{day}^{-1}$, measured by the difference between two-phase means. For the variance change, the early period of 1960 - 1992 on CPT Var displays a weaker amplitude when compared to the late period of 1993 - 2009. The intensity computed using divided variances is $14.15\left(\mathrm{~mm} \mathrm{day}^{-1}\right)^{2}$ (Fig. $\left.7 \mathrm{~b}\right)$. We believe the extended amplitude represents an increase in the intensity switching from drier to wetter, with the climate becoming more extreme after 1993.
To illustrate the local extreme parameters, we followed the CPT analysis processes on the 4 regions of Taiwan (refer to Fig. 5e). Table 2 summarizes the CPT and PI analysis for this study on the TCCIP_5 $\mathrm{km}$ dataset regionally. The CPT_Mean represents similar positions over western Taiwan (NOR: 2003; CEN: 2003; and SOU: 2004), excluding the eastern area (EAS: 1966). To measure the strength, we define the change between two periods, which are separated by change positions (CPT_Mean computed by means and CPT_Var by variances) as the change intensity. The intensities increase southward [NOR: 17.18; CEN: 26.35; and SOU: $28.57\left(\mathrm{~mm} \mathrm{day}^{-1}\right)$ ] over western Taiwan, which is consistent with the regional detection of linear PI trends [NOR: 0.17; CEN: 0.3; and SOU: $0.43\left(\%\right.$ year $\left.^{-1}\right)$ ] on 50year periods. In addition, CPT_Var also reveals the change signals at the time points of 2000 and 2004 over CEN and SOU separately, which pass the $99 \%$ confident statistics test. Noteworthy, CEN presents the strongest variance intensity in Taiwan, which implies the combined probability for flood and drought after 2000. The regional mean PI regression slope displays the highest sensitivity to climate change over EAS (4.57 mm day ${ }^{-1} \%$ ), and the largest variability over SOU $\left(0.43 \%\right.$ year $\left.^{-1}\right)$. The extreme climate detectors are also concerned with the associated 10-year return values (RV10), and the largest RV10 value is found over EAS (Table 2). The highest 10-year precipitation reappearance is over EAS $441.89 \mathrm{~mm} \mathrm{day}^{-1}$.

Although we mentioned the extreme rainfall (rx1day) climatology trend and variance, the attributions cannot explain clearly. In the metrology phenomena concept most of the rx1day in Taiwan is contributed by typhoon rainfall, while some are caused by annual Mei-Yu fronts, MCS and southwest flows. From a statistical standpoint, different sample sizes are sensitive to the change-point analysis. These factors can affect the detected results if correlated to the typhoon frequency. The PI area-average on CPT over Taiwan provides information on the statistical abrupt-shift in climate variability, but not on the specific phenomena change. If we could extract the annual typhoon rainfall contribution from the rx1day, it will be more consistent with the abrupt-shift result from previous research.

\subsection{Observed and Modeled Trends}

The PI parameter in spatial scale between datasets was calculated using the original grids of each CGCM. Afterwards, the area-mean over Taiwan was inserted into a $5 \mathrm{~km} \times 5 \mathrm{~km}$ resolution. The same observation period (TCCIP_5km) was then fitted into 50-year historical (ALL) and 91-year future projections (RCP45 and RCP85). Since most ALL models are available at the end of 2005, we extended 2009 using RCP85 simulations to maintain consistency with the observations.

In the present climate, anomaly fluctuations were 

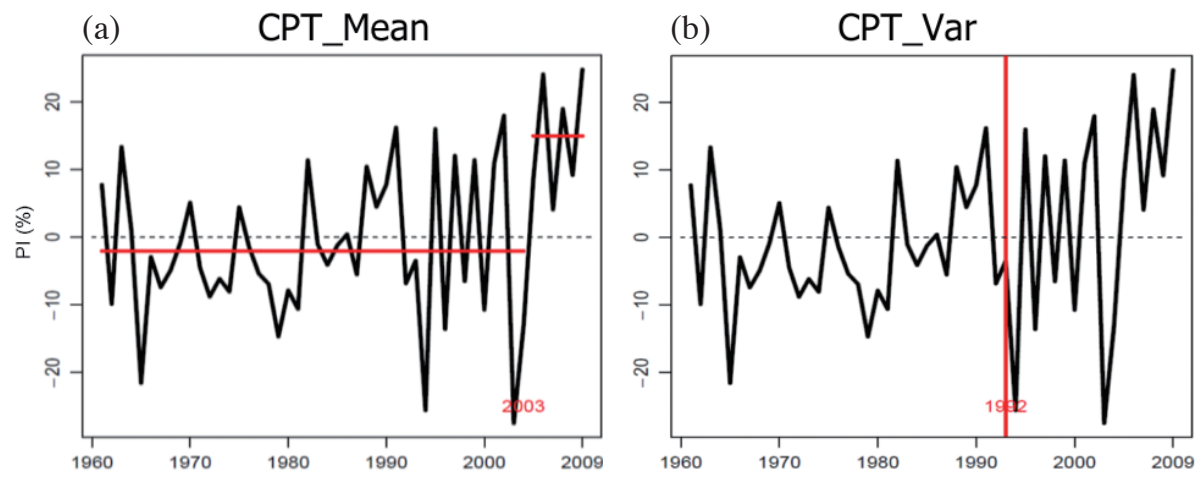

Fig. 7. Time series of TCCIP_5km area-averaged PI anomaly (black line) and result of change-point analysis (CPT, red lines). The mean state abrupt ship displays in (a) and (b) represent in variance from the divided periods. The divided year passed $99 \%$ significant test in whole time series.

Table 2. Summary for the area time series of change-point analysis (CPT) in mean state and variance, 10-year return value, regression slope and linear trend over four divided regions (NOR, CEN, SOU, EAS) and whole area mean (TW).

\begin{tabular}{|c|c|c|c|c|c|c|}
\hline & & NOR & CEN & SOU & EAS & TW \\
\hline \multirow{2}{*}{ CPT Mean } & Position (year) & 2003 & 2003 & 2004 & 1966 & 2003 \\
\hline & Intensity $\left(\mathrm{mm} \mathrm{day}^{-1}\right)$ & 17.18 & 26.35 & 28.57 & 10.34 & 17.02 \\
\hline \multirow{2}{*}{ CPT Variance } & Position (year) & NA & 2000 & 2004 & NA & 1992 \\
\hline & Intensity $\left[\left(\mathrm{mm} \mathrm{day}^{-1}\right)^{2}\right]$ & NA & 50.20 & 17.32 & NA & 14.15 \\
\hline \multicolumn{2}{|c|}{ Regression slope $\left[\left(\mathrm{mm} \mathrm{day}^{-1}\right) \%^{-1}\right]$} & 2.31 & 2.26 & 3.10 & 4.57 & 2.96 \\
\hline \multicolumn{2}{|c|}{ Trend $\left(\%\right.$ year $\left.^{-1}\right)$} & 0.17 & 0.30 & 0.43 & 0.13 & 0.25 \\
\hline \multicolumn{2}{|c|}{10 years $R V\left(\mathrm{~mm} \mathrm{day}^{-1}\right)$} & 253.08 & 259.50 & 328.08 & 441.89 & 331.39 \\
\hline
\end{tabular}

demonstrated and the 1960 - 2009 period was treated as the base period. The increasing PIs were represented in the time series for future projections. The spread of 16 models in the 20-year running mean on PIs (Fig. 8) displayed a smooth and slow trend in the long-term present climate pathway. The observation (TCCIP_5km) obviously revealed a positive trend, but contained a multi-models variance. The equalweight MMEs are displayed by thick-solid lines, while the associated model diffusions are shaded. The present climate observation shows a steeper curve with MME (ALL), yet, it is comprised of the diffused 16 models. This may be caused by the coarse resolution and missing precipitation contributed by typhoons, Mei-Yu fronts and southwest flows of CGCMs (Stocker et al. 2013; Tung et al. 2014). However, the increase observation trend is higher than ALL even in the RCP45 and RCP85 experiments. The variance in rx 1day extracted using low-resolution CGCM simulations provide useful information. The high-resolution simulations can be used for consist the precipitation insensitive with the complex terrain of Taiwan induces heavy rainfall in the future.

The $21^{\text {st }}$ century was divided into three stages to examine the future time periods: early century (EC, 2016 - 2035), medium century (MC, 2046 - 2065), and late century (LC, 2081 - 2100) in the long-term simulation. The PI time se- ries follow the emission pathway in two distinct scenarios (RCP45 and RCP85). Since the climate sensitivities are similar (the regression slops are 1.17 and $1.07 \mathrm{~mm}^{-1 a y}{ }^{-1} \%^{-1}$ in RCP45 and RCP85 MME dividedly), the PIs can be interpreted in the scenario pathways directly. In contrast to the present climate (ALL), the increasing PI discovers before MC linearly and attended 10\% in the RCP45 scenario, then remains stable and decreases slightly at $8 \%$ in LC (Fig. 8). However, a similar trend was also found from EC to MC, where it continued to rise at LC (14\%) in the RCP85 scenario. Opposite to the global change pathways on rx5day (Stocker et al. 2013), the increasing rx1day trend over Taiwan is weaker, which represents the local and geographical uncertainty parameter in future projections. Recent studies (Murakami et al. 2011; Stocker et al. 2013) show the total annual tropical storm frequency drops at LC in WNP, which demonstrates the probability of tracks in the vicinity of Taiwan and the associated extreme rainfall being weaker than the global scale.

Figure 9 estimates the uncertainty in four periods in the present (ALL) and future (RCP45 and RCP85) scenarios using boxplot. The period means of 16 models are presented to demonstrate the confidence levels. In view of the consistency for the entire time period; only 20-year (PC denotes 


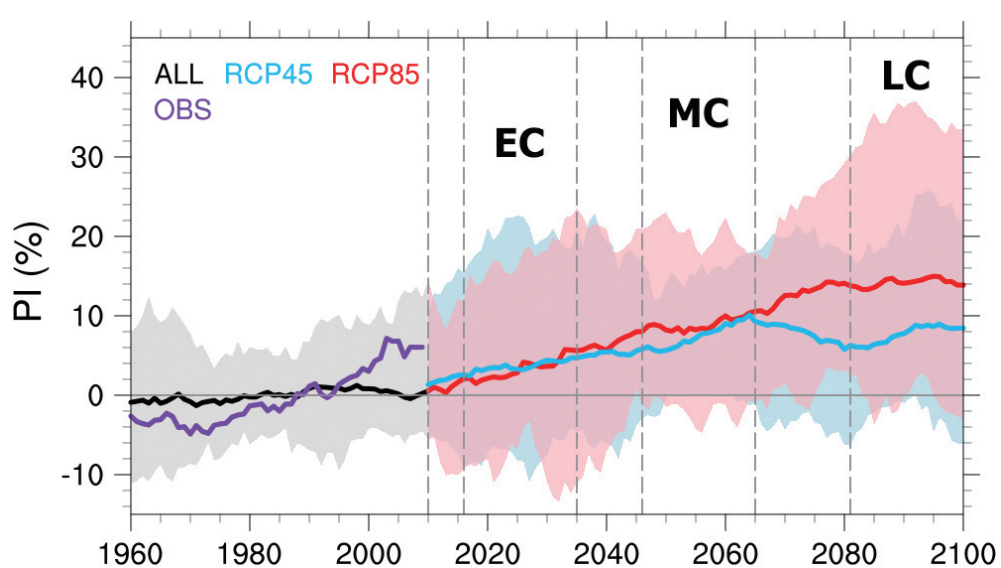

Fig. 8. Twenty-year PI anomaly running mean of ALL (black line) in present climate (1960 - 2009) of 16 CMIP5 models, RCP 45 (light blue line) and RCP85 (red line) scenarios represent the future projection (2010 - 2100). The OBS (purple line) represents TCCIP_5km area mean time series. The future projection period is divided into three stages in early $21^{\text {st }}$ century (EC, $\left.2016-2035\right)$, medium $21^{\text {st }}$ century (MC, 2046 - 2065), and late $21^{\text {st }}$ century (LC, $\left.2081-2100\right)$. The shaded of time series represents the spreads of 16 models in each time step over Taiwan.

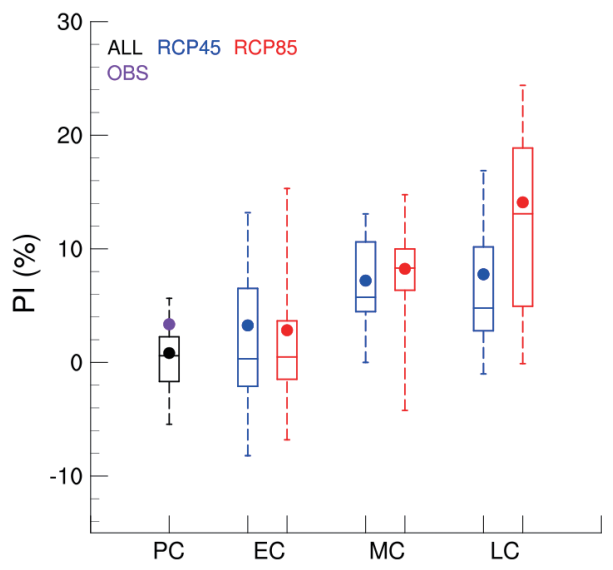

Fig. 9. The boxplot implies the uncertainty of PI anomaly on multi-model. Three scenarios represent ALL (black), RCP45 (blue), and RCP85 (red) on the period means of 1990 - 2009 (PC), 2016 - 2035 (EC), 2046 - 2065 (MC), and 2081 - 2100 (LC). The whiskers represent the range 5 - $95 \%$ ranges and the boxes denote 25,50 , and 75 percentiles on 16 models. The solid-dots display the period means of observation (TCCIP_5km) and MMEs.

1990 - 2009) of ALL in the end $20^{\text {th }}$ to early $21^{\text {st }}$ century are used. The performance follows the 20 -year running mean anomaly time series (Fig. 8) that weakly amplifies from -2 to $2 \%$ for the historical simulations. Although TCCIP_5km (OBS) cannot be accommodated to the contrast interval (from 25 to 75 percentile) of ALL, the coarse CGCMs display a strong performance (between 5 to 95 percentile) to simulate the extreme rainfall intensity over Taiwan. In the RCP45 scenario, the models represent extended uncertainty in EC; then produce consistent signals and decreasing trend after MC. RCP85 presents an increasing trend after MC and expends the uncertainty in LC in contrast, which implies that MC is the key stage in different pathways. We are also concerned about whether MMEs display statistical significance. Each specific box is divided into two parts by 50 percentile, which implies statistical multi-model concentrated deviation. The MME locations in RCP45 lie in the upper part of the boxes in all time periods. This is indicative of the MMEs being overestimated for most multi-models, but will at least accommodate a contrast interval. The MMEs of the RCP85 show more significance before MC.

In the uncertainty analysis, increasing PI trends are seen in all scenarios from EC to MC. Although the heavy RCP85 emission scenario shows a large uncertainty at LC, a higher confidence level is presented from $\mathrm{EC}$ to $\mathrm{MC}$ than RCP45 in the increasing pathway trend.

\section{CONCLUSION}

This study used a statistical methodology to standardize the rx1day using the PI, validated with observation data, applying it to detect past climate variability in the Taiwan area, 
and finally evaluated future projections in different climate change pathways.

The incomparable fluctuation amplitudes of rxlday anomalies at different stations make it difficult to represent the averaged characteristics of large areas. On the other hand, fluctuation in the PI anomaly, a standardized variable, from different stations or grid points are comparable, allowing the area-averaged PIs to properly present the features of extreme events over large areas. The high correlation coefficients $(0.79)$ between the two observed datasets (TW_STN and TCCIP_5km) demonstrate that the PI can not only represent the initial performance of the rx1day, but also denote the area-mean climate change over Taiwan. In climate variability detection, there is no distinct linear trend for the 5-year mean at each sub-region before the end of $20^{\text {th }}$ century. CPT analysis over Taiwan detects the change-mean location, which passes the significant test and changes to a different climate regime in 2002 - 2003, the intensity is $17.02 \mathrm{~mm} \mathrm{day}^{-1}$. The center-south alpines and southern Taiwan present positive trends exceeding $0.4 \%$ year $^{-1}$.

The PI projections from 16 CMIP5 CGCMs over Taiwan were evaluated to examine the climate variability and changes in extreme precipitation events. At the end of the $20^{\text {th }}$ century the variation in simulated PIs is smaller than the observed one, probably caused by the low GCM resolution and lack of typhoon rainfall contributions. In the future projection, PIs for all scenarios show similar increasing trends in the early and mid- $21^{\text {st }}$ century, reaching $10 \%$ by 2065 with higher confidence level in the RCP8.5 scenario. However, after 2065, PIs keep rising in the RCP85 scenario and reach $14 \%$ at the end of $21^{\text {st }}$ century, but showing insignificant trends in RCP4.5 scenario.

Acknowledgements We appreciate all comments from the Anonymous Reviewers. Y. S. Tung is supported by the Taiwan Climate Change Projection and Information Platform Project (TCCIP) program (MOST103-2621-M-865-001 and MOST 104-2621-M-865-001). We also acknowledge the Canadian Centre for Climate Modeling and Analysis (CCCMA) for providing the Climate Extreme Indices (CLIMDEX) dataset.

\section{REFERENCES}

Chen, C. J. and M. M. Lu, 2007: Detection of the climatic extreme rainfall events in Taiwan. Atmos. Sci., 35, 105-117.

Chu, L. F., M. McAleer, and S. H. Wang, 2013: Statistical modelling of recent changes in extreme rainfall in Taiwan. IJESD, 4, 52-55, doi: 10.7763/IJESD.2013. V4.302. [Link]

Ducré-Robitaille, J. F., L. A. Vincent, and G. Boulet, 2003: Comparison of techniques for detection of discontinuities in temperature series. Int. J. Climatol., 23, 1087-
1101, doi: 10.1002/joc.924. [Link]

Endo, N., B. Ailikun, and T. Yasunari, 2005: Trends in precipitation amounts and the number of rainy days and heavy rainfall events during summer in China from 1961 to 2000. J. Meteorol. Soc. Jpn., 83, 621-631, doi: 10.2151/jmsj.83.621. [Link]

Endo, N., J. Matsumoto, and T. Lwin, 2009: Trends in precipitation extremes over Southeast Asia. SOLA, 5, 168171, doi: 10.2151/sola.2009-043. [Link]

Fischer, E. M. and R. Knutti, 2015: Anthropogenic contribution to global occurrence of heavy-precipitation and high-temperature extremes. Nat. Clim. Change, 5, 560564, doi: 10.1038/nclimate2617. [Link]

Freychet, N., H. H. Hsu, C. Chou, and C. H. Wu, 2015: Asian summer monsoon in CMIP5 projections: A link between the change in extreme precipitation and monsoon dynamics. J. Climate, 28, 1477-1493, doi: 10.1175/JCLI-D-14-00449.1. [Link]

Jiang, D. and Z. Tian, 2013: East Asian monsoon change for the 21st century: Results of CMIP3 and CMIP5 models. Chin. Sci. Bull., 58, 1427-1435, doi: 10.1007/ s11434-012-5533-0. [Link]

Kharin, V. V., F. W. Zwiers, X. Zhang, and M. Wehner, 2013: Changes in temperature and precipitation extremes in the CMIP5 ensemble. Clim. Change, 119, 345-357, doi: 10.1007/s10584-013-0705-8. [Link]

Killick, R. and I. A. Eckley, 2014: Changepoint: An R Package for changepoint analysis. J. Stat. Software, 58, 1-19, doi: 10.18637/jss.v058.i03. [Link]

Kitoh, A. and T. Uchiyama, 2006: Changes in onset and withdrawal of the East Asian summer rainy season by multi-model global warming experiments. J. Meteorol.Soc. Jpn., 84, 247-258, doi: 10.2151/jmsj.84.247. [Link]

Knutti, R., R. Furrer, C. Tebaldi, J. Cermak, and G. A. Meehl, 2010: Challenges in combining projections from multiple climate models. J. Climate, 23, 2739-2758, doi: 10.1175/2009JCLI3361.1. [Link]

Lee, J. Y. and B. Wang, 2014: Future change of global monsoon in the CMIP5. Climate Dyn., 42, 101-119, doi: 10.1007/s00382-012-1564-0. [Link]

Liu, S. C., C. Fu, C. J. Shiu, J. P. Chen, and F. Wu, 2009: Temperature dependence of global precipitation extremes. Geophys. Res. Lett., 36, L17702, doi: 10.1029/2009GL040218. [Link]

Lu, M. M., C. J. Chen, and Y. C. Lin, 2007: Long-term variations of the occurrence frequency of extreme rainfall events during the period of 1951-2005. Atmos. Sci., 35, 87-103.

Meehl, G. A., T. Karl, D. R. Easterling, S. Changnon, R. Pielke Jr., D. Changnon, J. Evans, P. Ya. Groisman, T. R. Knutson, K. E. Kunkel, L. O. Mearns, C. Parmesan, R. Pulwarty, T. Root, R. T. Sylves, P. Whetton, and F. Zwiers, 2000: An introduction to trends in 
extreme weather and climate events: Observations, socioeconomic impacts, terrestrial ecological impacts, and model projections. Bull. Amer. Meteorol. Soc., 81, 413-416, doi: 10.1175/1520-0477(2000)081<0413:AI TTIE > 2.3.CO;2. [Link]

Miao, C., Q. Duan, Q. Sun, Y. Huang, D. Kong, T. Yang, A. Ye, Z. Di, and W. Gong, 2014: Assessment of CMIP5 climate models and projected temperature changes over Northern Eurasia. Environ. Res. Lett., 9, doi: 10.1088/1748-9326/9/5/055007. [Link]

Min, S. K., X. Zhang, F. W. Zwiers, and G. C. Hegerl, 2011: Human contribution to more-intense precipitation extremes. Nature, 470, 378-381, doi: 10.1038/nature09763. [Link]

Min, S. K., X. Zhang, F. Zwiers, H. Shiogama, Y. S. Tung, and M. Wehner, 2013: Multimodel detection and attribution of extreme temperature changes. J. Climate, 26, 7430-7451, doi: 10.1175/JCLI-D-12-00551.1. [Link]

Murakami, H., B. Wang, and A. Kitoh, 2011: Future change of western North Pacific typhoons: Projections by a 20-km-mesh global atmospheric model. J. Climate, 24, 1154-1169, doi: 10.1175/2010JCLI3723.1. [Link]

Shiu, C. J., S. C. Liu, and J. P. Chen, 2009: Diurnally asymmetric trends of temperature, humidity, and precipitation in Taiwan. J. Climate, 22, 5635-5649, doi: 10.1175/2009JCLI2514.1. [Link]

Sillmann, J., V. V. Kharin, X. Zhang, F. W. Zwiers, and D. Bronaugh, 2013a: Climate extremes indices in the CMIP5 multimodel ensemble: Part 1. Model evaluation in the present climate. J. Geophys. Res., 118, 1716-1733, doi: 10.1002/jgrd .50203. [Link]

Sillmann, J., V. V. Kharin, F. W. Zwiers, X. Zhang, and D. Bronaugh, 2013b: Climate extremes indices in the CMIP5 multimodel ensemble: Part 2. Future climate projections. J. Geophys. Res., 118, 2473-2493, doi: 10.1002/jgrd.50188. [Link]

Stocker, T. F., D. Qin, G. K. Plattner, L. V. Alexander, S. K. Allen, N. L. Bindoff, F. M. Bréon, J. A. Church, U. Cubasch, S. Emori, P. Forster, P. Friedlingstein, N. Gil- lett, J. M. Gregory, D. L. Hartmann, E. Jansen, B. Kirtman, R. Knutti, K. K. Kumar, P. Lemke, J. Marotzke, V. Masson-Delmotte, G. A. Meehl, I. I. Mokhov, S. Piao, V. Ramaswamy, D. Randall, M. Rhein, M. Rojas, C. Sabine, D. Shindell, L. D. Talley, D. G. Vaughan, and S. P. Xie, 2013: Technical Summary. In: Stocker, T. F., D. Qin, G. K. Plattner, M. Tignor, S. K. Allen, J. Boschung, A. Nauels, Y. Xia, V. Bex, and P. M. Midgley (Eds.), Climate Change 2013: The Physical Science Basis, Contribution of Working Group I to the Fifth Assessment Report of the Intergovernmental Panel on Climate Change, Cambridge University Press, Cambridge, United Kingdom and New York, NY, USA, 33-115.

Su, S. H., H. C. Kuo, L. H. Hsu, and Y. T. Yang, 2012: Temporal and spatial characteristics of typhoon extreme rainfall in Taiwan. J. Meteorol. Soc. Jpn., 90, 721-736, doi: 10.2151/jmsj.2012-510. [Link]

Tu, J. Y., C. Chou, and P. S. Chu, 2009: The abrupt shift of typhoon activity in the vicinity of Taiwan and its association with western North Pacific-East Asian climate change. J. Climate, 22, 3617-3628, doi: 10.1175/2009JCLI2411.1. [Link]

Tung, Y. S., C. T. Chen, and P. C. Hsu, 2014: Evolutions of Asian summer monsoon in the CMIP3 and CMIP5 models. SOLA, 10, 88-92, doi: 10.2151/sola.2014-018. [Link]

Weng, S. P. and C. T. Yang, 2012: The construction of monthly rainfall and temperature datasets with $1 \mathrm{~km}$ gridded resolution over Taiwan area (1960-2009) and its application to climate projection in the near future (2015-2039). Atmos. Sci., 40, 349-369.

Westra, S., L. V. Alexander, and F. W. Zwiers, 2013: Global increasing trends in annual maximum daily precipitation. J. Climate, 26, 3904-3918, doi: 10.1175/JCLID-12-00502.1. [Link]

Zhai, P., X. Zhang, H. Wan, and X. Pan, 2005: Trends in Total Precipitation and Frequency of Daily Precipitation Extremes over China. J. Climate, 18, 1096-1108, doi: 10.1175/JCLI-3318.1. [Link] 